\title{
Determinants of Micro-Enterprise Cluster Innovation: Analysis of Member Identification and Satisfaction of Leadership
}

\author{
Yao-Chin Lin, Wei-Hung Chen, Wei-Chun Liu, and Ching-Feng Lin
}

\begin{abstract}
This research focuses on cluster, and explores the determinants of Micro-Enterprise Cluster Innovation through interviews to explore member identification and satisfaction of leadership. The research method used interviews to collect views of six members on the diffusion of e-commerce. This research found that: 1 . Relationship between cluster leader's satisfactions is high. 2. Members believe that the importance of leaders in cluster innovation is higher than their importance. 3. The key factors for innovation success are leader and members, leader, consensus, self-capability, cooperation. Finally, this research proposes theoretical, practical implications and recommendations for future research.
\end{abstract}

Index Terms-Micro-Enterprise, cluster leader, cluster member.

\section{INTRODUCTION}

The research pointed out that industrial clustering has made a significant contribution to the growth of advanced countries and emerging economies, and it is worth the cooperation between governments, enterprises and the public to create Shared value with innovative thinking [1]. They analyzed and discussed the mutual relations among leaders, members and consultants and their influence on the performance of clustering by using Investigate, Design, Execute and Adjust (IDEA) cycle model, and found that the key to cluster performance is the role of cluster leader, which will affect the members' belonging and identity [2]. The research points out that four modes of promoting innovation and sustainable development can be concluded in the objective evaluation of marketing ability, information ability, management ability and driving force of cluster leader [3]. Therefore, by exploring the following four questions, this research tries to find out the key tips for micro business leaders to effectively lead groups, so as to assist the government to grasp specific factors accurately and increase the investment efficiency of micro business venture budget.

1. What is the relationship between cluster leader and members?

2. What is the satisfaction of the cluster members with the leader?

3. What is importance of Leader and member's selfimportance in cluster innovation?

4. What is key factor in innovation achievement of cluster?

Manuscript received November 15, 2018; revised January 8, 2019

The authors are with the Yuan Ze University, Taoyuan City, Taiwan. (e-mail: lyaochin@gmail.com, wehchen123@gmail.com, michaelliubid@gmail.com, sandergoog@gmail.com).

\section{LITERATURE REVIEW}

\section{A. Micro-enterprise Cluster and Innovation}

There are different definitions of the number of micro-enterprise employees in the world. The organization for economic cooperation and development defines a micro-enterprise as an employee that employs fewer than 20 people. MIE is a business with five or fewer employees. MIE is at the forefront of the entrepreneurial formation process and can be found in urban and rural areas in both developed and developing countries. According to the survey results of the white paper on SMEs of 2017, SMEs account for $97.7 \%$ of all enterprises in Taiwan, and accounted for $78 \%$ of the Taiwan employment. In developing countries, successful micro-enterprises are the main driving force for employment growth, yet micro-enterprises continue to face problems of limited resources, low capacity and lack of innovative vision. Small and Medium Enterprise Administration under the Ministry of Economic Affairs (MOEASMEA) points out that MIE's operating difficulties include marketing, loans, lack of ICT and lack of expertise. To overcome these problems, MOEASMEA use clustering strategy. Most multilateral entities and small and medium-sized enterprises operate in the same or interrelated fields, and geographical characteristics facilitate clustering. In addition, MOEASMEA also provides power for a cluster of MIE with no more than five employees, such as providing low-interest start-up loans and exclusive consulting services of up to 1 million New Taiwan Dollar [4]. Clustering is a geographically concentrated phenomenon of interconnected corporate machines in a particular domain.

The research argues that the huge benefits of clustering in advanced countries will not be lower than in emerging economies. Enterprise productivity and innovation ability are highly affected by cluster. Clustering refers to the concentration of industry, related enterprises, suppliers, service providers and logistics infrastructure in a certain area, including academic courses, industrial organizations, standards organizations and other institutions and various public assets in a certain area. Companies build clusters to improve productivity while creating Shared value. The establishment of a fair and free market usually requires the cooperation of many partners, the enterprise will have reliable supply, and the supplier has the motivation to improve quality and efficiency. The cooperation between the government and the people creates Shared value. The best opportunities for companies to create Shared value often require collective action from multiple parties, and companies should try to find partners. Collective development plans, coordinated by the 
private sector, industrial organizations, government agencies and non-governmental organizations, are most successful [5].

The research proposed the necessity of micro-enterprise innovation, which is also the key to cluster innovation. The research in India proves the importance of knowledge sharing and effective innovation of micro-enterprises when they are ready to face entrepreneurial challenges. Because cluster innovation is different from general organization innovation, only innovation action can benefit all cluster members [6].

They classified innovation into three aspects: sustainable development driven innovation, thrifty innovation and social driven innovation [7]. The research revised the model into thrifty innovation, social driven innovation and cooperative innovation [8]. Finally, through case analysis, a new grassroots innovation model is formed, namely thrifty innovation, social driven innovation and cooperative innovation, which is called micro-enterprise innovation model.

The research was designed to help middle-aged start-up women in Yilan and Hualien, who have low incomes and low education levels. In addition, the cluster members are micro-enterprises that lack resources and capital. They innovate from their own products. Clustering is in line with the innovation of frugal innovation and social driven innovation proposed by [12]. Cluster innovation leaders and members to discuss matters with cluster leaders and transformational leadership have a high cluster discrimination member collaboration innovation, through the cooperative innovation, the results showed that cluster leadership and identification can promote and strengthen the cluster innovation, and cluster the leader's leadership style is more important. This research defines of the cluster innovation: the innovation performance conducted through the collaboration of both cluster leader and members.

\section{B. Relationship between Cluster Leader and Members}

They pointed out that and discussed how to improve the digital capability of SME's through tutoring and activities [9]. The research analysis and discussion of the IT therapy structure and coaching mode proposed in the research of the use of ICT in micro-enterprises [10]. The results showed that in addition to the significant improvement in digital capability, the cluster members were able to verify the effectiveness of innovation diffusion theory and it therapy because of their leaders' characteristics.

The research divided technical capacity into ICT and non-ICT. Personal technical ability refers to the use of modern technology and services, etc. For a company, technical ability refers to the information of the company and the use of technology by employees to make the company profitable [11].

Strategically the various technology used for commercial purposes, the enterprise is a very complicated technical foundation. In Mithas et al research, ICT skills including the use of the internal network and external network, ER, SCM, e-commerce and other related technology applications, especially for small businesses through ICT capacity, they are mainly associated with the use of ICT, in order to improve the internal efficiency, and improve the internal and external communication [12].
Non-ICT capability refers to other capabilities besides ICT, including product and brand design, brand marketing, etc. In addition to the clustering partners, The research proposed that the number of customers, monthly sales and other financial indicators are one of the indicators to evaluate organizational performance [12], [13].

They using the IPO (In - Process - Output pattern) analysis of cluster using $\mathrm{O} 2 \mathrm{O}$ e-commerce on the performance of clustering, the results proposed cluster has three types: the brand mode, cluster innovation mode and mode of e-commerce platform for the performance of clustering, the results put forward cluster has three types: brand mode, cluster innovation mode and e-commerce platform mode driver is defined as members of the leadership, this research requirements, and knowledge sharing. Competence means management, product design, marketing, branding and IT [11].

In terms of ability, objective evaluation refers to the ability to lead a group of leaders in marketing, information and management, while the driving force refers to the four modes to promote the sustainable development of grassroots innovation by means of performance, member needs and sharing.

1) Mode I, with high capability and driving force, is defined as "sustainable". It is a model of independent operation and a demonstration of sustainable development.

2) Mode II is high in capability and low in drive. It is defined as "capability" that can be promoted through government incentives and become a type of sustainable development.

3) Model III, with low capability and driving force, is defined as "start" type. This type of ability is low and the driving force is insufficient.

4) Model IV, with low capability and high driving force, is defined as a "leadership" type. It can carry out cooperative innovation through strategies (such as cross-group cooperation) to promote the formation of cluster sustainable development.

They pointed out that the relationship between leaders' consultants and their members and their influence on the performance of clustering, and discussed the influence of enterprise clustering on the relationship between the three roles. The research method uses IDEA cycle for data analysis [2]:

1) I-investigation: investigate the facts required to thoroughly analyze the problem. The facts may include: problems, customers, needs, goals, etc.

2) D-design: design tools to help find solutions based on the results of the previous phase.

3) E-execution: this phase will be conducted as an experimental or prototype method and will be tested on a small scale.

4) A - adjustment: if positive results are found, the solution should be adjusted to bring it closer to the standards of the forthcoming product or service.

Leadership style is important, and a group leader can act as a match, organizer, developer, facilitator and integrator, depending on the needs of the group. A reference discussed the role and purpose of cluster facilitator in leading different cluster types, as well as the impact of cluster leadership 
changes [14]. As shown in the table 1. There are four different types of group leaders with different attributes and abilities, and different activities to achieve different goals.

TABLE I: CLUSTER FACILITATOR ROLES AND PURPOSES

\begin{tabular}{ll}
\hline $\begin{array}{l}\text { Cluster } \\
\text { facilitator roles }\end{array}$ & Cluster facilitator purposes \\
\hline Match maker & $\begin{array}{l}\text { To seek for new cooperative relationships with both } \\
\text { internal and external members of the cluster and to } \\
\text { widen market opportunities. }\end{array}$ \\
\hline Organizer & $\begin{array}{l}\text { To plan, set up and execute cluster activities such as } \\
\text { networking events, seminars, fundraising, projects } \\
\text { or research trips for the cluster participants. }\end{array}$ \\
\hline Developer & $\begin{array}{l}\text { To design and conduct projects to support cluster } \\
\text { goals. }\end{array}$ \\
\hline Promoter & $\begin{array}{l}\text { To launch projects which aimed to lower the barriers } \\
\text { to cooperation and to encouraging the branch firms } \\
\text { to contract with the small and medium-sized as } \\
\text { suppliers. }\end{array}$ \\
\hline Integrator & $\begin{array}{l}\text { To overcome and remove the sectoral boundaries } \\
\text { between members and translate their different needs } \\
\text { so as to integrate the market knowledge, resources, } \\
\text { technical knowledge of the actors. }\end{array}$ \\
\hline \hline
\end{tabular}

Source: Ingstrup (2013) P147.

Research found that cluster leader, mainly in the "attitude" will affect members, consultants in "ability" affected members, members of the cluster (behavior) of cluster activities into attitude is an important key of cluster development, importance, the research found that the key factors influencing the cluster performance is a cluster of "belonging" and "identity", especially the leader's role is more important, are the cluster key success factors. This research defines of the cluster leader: They are based on trust and have the enthusiasm for service and willing to pay their feelings and actions to agglomerate the consensus and development goals of the group.

\section{METHODOLOGY}

\section{A. Research Design}

The research structure is the influence of the cluster members on the cluster innovation. The mediator variable is the cluster leader, which mainly discusses the role of the leader in the cluster innovation, and interviews the members of the cluster on the leadership characteristics, capabilities and satisfaction. To understand the importance of leader and themselves in cluster innovation. Finally ask key factor in innovation achievement. The research model is shown in Fig 1.

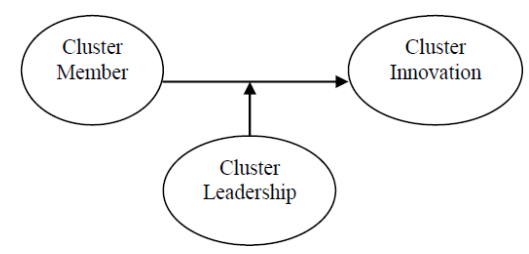

Fig. 1. Research Model.

The main interview questionnaires include:

1) What is the percentage of time you spend in the cluster?

2) What is the percentage of effort you spend in the cluster?

3) What is the operating mode of the cluster?

4) What are the aspects of concern of the leader? Do these concerns increase the members' cluster identification?

5) How does the leader behaviors during the cluster regular meetings or activities? Do her performances increase the members' cluster identification?

6) What is the key factor for the achievement of cluster innovation?

7) What is the importance of the leader on the cluster innovation?

8) What is the importance of the members on the cluster innovation?

9) What is the members' satisfaction of the cluster leader?

TABLE II: COMPREHENSIVE ANALYSIS OF CLUSTER LEADER

\begin{tabular}{|c|c|c|c|c|}
\hline Cluster Member Code/Major Commodities & Engagement & Characteristics & Capabilities & Satisfaction \\
\hline $\begin{array}{l}\text { M1 } \\
\text { Energy jewelry and divine service }\end{array}$ & Counseling programs & $\begin{array}{l}\text { - Generous } \\
\text { - Persistence } \\
\text { - Straightforward }\end{array}$ & $\begin{array}{l}\text { - Experienced } \\
\text { - Good interpersonal relationship } \\
\text { - High effectiveness } \\
\text { - Leadership } \\
\text { - Artistic ability } \\
\end{array}$ & $70 \%$ \\
\hline $\begin{array}{l}\text { M2 } \\
\text { Fabric-related handicrafts }\end{array}$ & $\begin{array}{ll}\text { - } & \text { Exhibition } \\
\text { - } & \text { Provide communication } \\
& \text { opportunities }\end{array}$ & $\begin{array}{l}\text { - Generous } \\
\text { - Fair } \\
\text { - Responsible } \\
\text { - Earnest } \\
\text { - Flexible } \\
\end{array}$ & $\begin{array}{l}\text { - Leadership } \\
\text { - Experienced }\end{array}$ & $100 \%$ \\
\hline $\begin{array}{l}\text { M3 } \\
\text { Aluminum-related handicrafts }\end{array}$ & $\begin{array}{ll}\text { - } & \text { Courses } \\
\text { - } & \text { Application for counseling } \\
& \text { program } \\
\text { - } & \text { Brand promotion } \\
\end{array}$ & Patient & High sensitivity to the market & $80 \%$ \\
\hline $\begin{array}{l}\text { M4 } \\
\text { Leather-related handcrafts }\end{array}$ & $\begin{array}{l}\text { - Application of street artist } \\
\text { certificate } \\
\text { - Founding of the cluster }\end{array}$ & $\begin{array}{l}\text { - Enthusiasm } \\
\text { - Patient }\end{array}$ & $\begin{array}{l}\text { - Leadership } \\
\text { - Reliance }\end{array}$ & $90 \%$ \\
\hline $\begin{array}{l}\text { M5 } \\
\text { Clay-related handicrafts }\end{array}$ & $\begin{array}{l}\text { Preparation for regular } \\
\text { meetings and courses }\end{array}$ & $\begin{array}{ll}\text { - } & \text { Enthusiasm } \\
\text { - } & \text { Flexible } \\
\text { - } & \text { Fair } \\
\end{array}$ & $\begin{array}{l}\text { - Good interpersonal relationship } \\
\text { - Always comes up with good } \\
\text { ideas }\end{array}$ & $100 \%$ \\
\hline $\begin{array}{l}\text { M6 } \\
\text { Essential oils and pure dew essence }\end{array}$ & 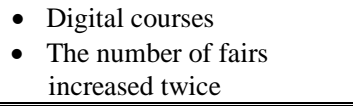 & Stubborn & $\begin{array}{l}\text { - Reliance } \\
\text { - Good interpersonal relationship }\end{array}$ & $90 \%$ \\
\hline
\end{tabular}

\section{B. Data Analysis Method}

In order to avoid the over-subjectivity of the researcher, this research applies the data triangulation in the data collection section, which is intended to verify the consistency 
of the different sources. These sources include:

1) Interview: This research adopts semi-structure interviews with the cluster leader and 6 cluster members. This research insists on obtaining a balance and fair result by ensuring that the participation time of members in the cluster do not affect their opinions on the cluster leadership and cluster identification by involving 3 old members and 3 new members.

2) Secondary data: Other than the data obtained from the interviews, the secondary data also has been used as a reference to better understand the cluster performance done and they are as follows: The cluster's proposal report, and the cluster's related website such as official website, fan pages and e-commerce platforms.

3) Observation: Direct observation was executed during both the fairs and the interviews processes. The results obtained were used to authenticate the answer provided by the members against the questionnaires about cluster interaction (identification).

This research method explores interviews, interviews 6 members of the cluster, and records, photographs, and produces verbatim manuscripts. Through the analysis of the verbatim manuscript, answer the research questions and form them into Tables II and Table III.

\section{FINDING}

\section{A. Relationship between Cluster Leader's Satisfaction Is High}

The relationship between leaders and members in the cluster is organized through the collected data. Table II shows the participation, characteristics, and abilities of the leaders extracted from the table. Members are generally satisfied with their cluster leader. Most members believe that consulting programs, courses, exhibitions and trade fairs are the reason for joining the cluster and are also considered to be the contributions of the leaders. In their view, the leader is a generous, flexible, enthusiastic and fair woman, with the ability to rely, good handicraft experience and good interpersonal relationships.

All members believe that cluster leaders are very important in cluster innovation. As shown in Table II, members believe that member cooperation is important and influential, although the key factor in cluster innovation is the leader.

\section{B. Members Believe that the Importance of Leaders in Cluster Innovation Is Higher than Their Importance}

Table III shows that the members of the group believe that the importance of leaders in clustering innovation is more than $70 \%$, and the importance of self is $50 \%-70 \%$. It is very important for leaders to be successful in clustering. In addition, the key factors for innovation success are leader and members, leader, consensus, self-capability, cooperation. The cluster carries out marketing innovation, product design innovation, technology and service innovation. They have begun and are interested in achieving more innovative performance over the years, including co-branding, exotic partnerships, integration of products and services in tourism, market innovation and more product innovation.
TABLE III: COMPREHENSIVE ANALYSIS OF CLUSTER INNOVATION

\begin{tabular}{lccc}
\hline \hline Member & $\begin{array}{l}\text { Importance of } \\
\text { Leader in Cluster } \\
\text { Innovation }\end{array}$ & $\begin{array}{c}\text { Self-importance in } \\
\text { Cluster Innovation }\end{array}$ & $\begin{array}{l}\text { Key Factor in } \\
\text { Innovation } \\
\text { Achievement }\end{array}$ \\
\hline M1 & $90 \%$ & $50 \%$ & $\begin{array}{c}\text { Leader and } \\
\text { members }\end{array}$ \\
\hline M2 & $90 \%$ & $60 \%$ & Leader \\
\hline M3 & $70 \%$ & $50 \%$ & Consensus \\
\hline M4 & $90 \%$ & $70 \%$ & Self-capability \\
\hline M5 & $100 \%$ & - & Cooperation \\
\hline M6 & $80 \%$ & $50 \%$ & Leader \\
\hline \hline
\end{tabular}

\section{CONCLUSION}

This paragraph outlines some important discussions of the results obtained and classifies them into two implications: theoretical and practical, to justify the applicability of the results. Next, the limitations of the study are listed and finally, the conclusions and future recommendations are enumerated.

\section{A. Conclusion and Discussion}

This research proposes the following four conclusions:

1. The key success factors of clustering innovation are mainly from the leadership of the cluster leaders. The satisfaction of the members of this research cluster is over $70 \%$, which proves that the key factor of cluster innovation lies in the display of leadership. The characteristics of leader: generous, persistence, straightforward, responsible, earnest, enthusiasm and flexible. It is an important factor affecting the clustering innovation. This also proves that positive personality traits can lead the innovation of cluster, and influence the innovative performance of members by the characteristics of leader.

2. The gathering leaders from the heart to create an atmosphere pay more attention to the inner needs of the members. The essence of the management of this group of leaders is to create a family atmosphere from the heart, to provide a variety of active care and effective help for the members of the group, so that everyone can actively participate in the work. Moreover, when creating an atmosphere, we pay more attention to the inner needs of our members, and we will act with sincerity and sincerity through practical means.

3. This research found that the leader of the group has a trait: flexibly showing weaknesses helps to unite and unite in innovation. A number of members gathered in the interview: the cluster leaders have workaholics, but the family members of the group members have priority (Leaders will not be strong at this time), and the leaders mentioned many times during the public meeting: they are very enthusiastic at work, but sometimes it is too stubborn to lose patience, I hope everyone can understand. At the same time, many members of the group are more united and more helpful in creating an innovative atmosphere.

4. For the focus on innovation, the importance of leaders is greater than the members of the cluster. Finally, the members of the cluster believe that the importance of leaders in cluster innovation is as high as $70 \%$, which shows the importance of leader in innovation, but members believe that their importance is less than $70 \%$. The key success factors in 
innovation are: leader and members, leader, consensus, self-capability, cooperation.

\section{B. Theoretical and Practical Management Implications}

The research [6] proposes a cluster innovation model and the results of this research also prove the importance of cooperative innovation. Leadership is a key factor in innovation [14]. Because, in the formation process of the cluster, the leader is the key man and the leader convert members. The performance of the funds and external resources is excellent, and it also shows the coordination of internal capabilities. Secondly, it will be because the weak micro-enterprises, who are not aware with business management and technology. They will develop clusters with leaders as the center, have common goals, and are also the characteristics of this research member. However, this research infers that the possible purpose of leaders' organization is to achieve corporate social responsibility, self-realization, and to get better resources for their own businesses.

Why members of cluster innovation are less self-important, possibly because members are not confident, most are followers, unspectacular personality, or may be because of strong leader.

The key factors of innovation are the high-drive and low-capacity pattern in reference [12]. Leader is typical leader with strong leadership and strong drive-force, but lack of ability. The cluster gathers to do overall brand marketing and creates a cluster with the handwriting as the main product. Through the cross-industry integration of the entrepreneurial and network technology industries, the company has broken through the traditional channels, crossed the digital channels. And changed the "network" into a "channel" to promote the cluster brand to digital media and expand the benefits of joint marketing.

The theory to explore the role of the cluster leader, this research believes that the leader of the research case meets the five proposed by [13], since 1. Match maker: refers to the leader to seek for new cooperative relationships with both internal and external members of the cluster. 2. Organizer: Refers to the leader planning, setting up and executing cluster activities for the cluster participants. The case leader of this research obtained government counseling and educational training activities. 3. Developer: Leader set the goal of cluster and achieve it together. 4. Promoter: Assist members in the management of activities. 5. Integrator: Overcome and eliminate departmental boundaries between members, transform their different needs, and promote cluster cooperation.

\section{Future Research Recommendations and Limitations}

This research has discussed the importance of cluster leader with theoretical and practical implications, but there are still many issues that can be discussed in terms of the role of members of the cluster, such as the cluster recognition of members, self-awareness of members, etc. It is recommended that future research can discuss related issues.

The execution and achievement of the ongoing innovation activities can be followed up in the future, to determine the prediction of this study. Apart from this, this study only observed the interaction of the cluster members during the fair. Observation of interaction in regular meetings can be added to reinforce the strength of the cluster identification by observing the real interaction between the leaders and the members. Comparison between different clusters can be made to determine the influence of different leadership and cluster identification on innovation, and to explore other factors that influence the cluster identification as this study only involves leadership as the influencing factor.

The research limitation is mainly because the research on micro-enterprise cluster is not enough to infer to other types of cluster. In addition, the number of samples taken in this research is 1 leader and 6 members, and some members are joined cluster for the newcomers who have been in the semi-annual period, this research is not enough to be inferred or generalized for case studies.

\section{REFERENCES}

[1] M. E. Porter and M. R. Kramer, "The big idea: Creating shared value," Harvard Business Review, 89, 2-17, 2011.

[2] Y. C. Lin, W. H. Chen, and C. F. Lin, "Determinants of consultant, leader and member by micro-enterprise cluster relationship and the development of cluster's performance," in Proc. 2018 7th International Conference on Business, Management and Governance, 2018.

[3] Y. C. Lin, C. L. Chen, and W. H. Chen, "The study on the sustainable patterns of grassroots innovations in the clusters of micro-enterprises," European Journal of Sustainable Development, vol. 7, issue 4, pp. 507-516, 2018.

[4] Small and Medium Enterprise Administration under the Ministry of Economic Affairs, The White Paper of Small and Medium Enterprise, 2018.

[5] M. E. Porter, "Clusters and the new economics of competition," Harvard Business Review, vol. 77, Nov./Dec. 1998.

[6] K. M. Rani, "Innovation in Indian women micro-enterprises," IPE Journal of Management, vol. 3, no. 2, pp. 76-94, 2013.

[7] M. Pansera and S. Sarkar, "Crafting sustainable development solutions: Frugal innovations of grassroots entrepreneurs," Sustainability, vol. 8, no. 1, 1-51, 2016.

[8] C. L. Chen, Y. C. Lin, W. H. Chen, and X. S. Heng, "Determinants of cluster leadership and identification on cluster innovation model," Organization Development Journal, vol. 39, no. 4, pp. 538-553, 2018.

[9] Y. C. Lin, W. H. Chen, and W. C. Liu, "Diffusion of e-commerce on micro-enterprise cluster innovation acceptance rate: A case study in Taiwan," in Proc. 2018 7th International Conference on Business, Management and Governance, 2018.

[10] W. Peter, M. Kamal, and S. Qureshi. "Meeting the challenges of ICT adoption by Micro-Enterprises," Journal of Enterprise Information Management, vol. 21, no. 6, pp. 616-632, 2008.

[11] Y. C. Lin, W. H. Chen, and X. S. Heng, "The impact of technological capabilities on online-to-offline commerce: A case of micro-enterprises' cluster performance," International Journal of e-Education, e-Business, e-Management and e-Learning, vol. 8, issue: 1, pp. 1-9, 2018.

[12] S. Mithas, N. Ramasubbu, and V. Sambamurthy, "How information management capability influences firm performance," MIS Quarterly, vol. 35, no. 1, pp. 237-256, 2011.

[13] J. Peters, M. Sievert, and C. Strupat, "Impacts of a micro-enterprise clustering programme on firm performance in ghana," European Journal of Development Research, vol. 27, no. 1, pp. 99-121, 2015.

[14] M. B. Ingstrup, "Facilitating different types of clusters," Management Revue, vol. 24, no. 2, pp. 133-150, 2013.

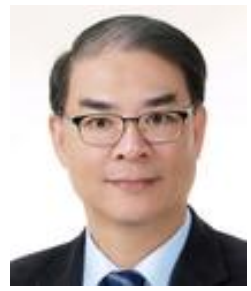

Yao-Chin Lin received his Ph.D. degree in business administration from National Cheng Chi University, Taiwan. His expert fields include business process reengineering, business process management, inter-organizational information design, and information technology application. He is an associate professor of the Department of Information Management, Yuan Ze University now. 


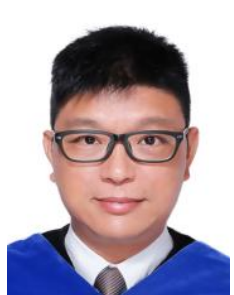

Wei-Hung Chen received his Ph.D. degree in the Department of Information Management, Yuan Ze University, Taiwan. His research focuses on the topic of cluster innovation, online-to-offline $(\mathrm{O} 2 \mathrm{O})$ commerce, small and medium-sized (and micro) enterprises, grassroots innovations and diffusion. $\mathrm{He}$ was the head of IT department, and has ISO 27001 and BS 10012 leader auditor certificate.

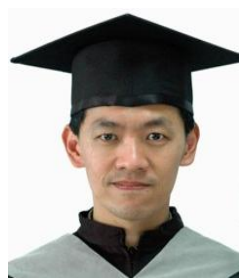

Wei-Chun Liu is currently studying a Ph.D. at the Department of Information Management, Yuan Ze University, Taiwan. His research focuses on the topic of Integrated Communication Systems, cyber security and grassroots innovations and diffusion. $\mathrm{He}$ was the head of IT department, and has ECIH, MCSE and MCSD certificate.
Ching-Feng Lin is currently studying a Ph.D. at the Department of Information Management, Yuan Ze University, Taiwan. His research focuses on enterprise change resistance, organizational behavior and business model innovation. He was the head of the IT department and is responsible for the software development and project management department, and has the ISO 9001-2015 version of the leader auditor certification. 